\title{
ANTIBACTERIAL ACTIVITY OF PSIDIUM GUAJAVA LINN. STEM BARK EXTRACTS ON MULTI DRUG RESISTANT (MDR) COMMUNITY ACQUIRED METHICILLIN-RESISTANT STAPHYLOCOCCUS AUREUS (CA-MRSA)
}

Chibuike Ibe ${ }^{1}$, Ngozi Lucy Maduagwu ${ }^{2}$

\section{HOW TO CITE THIS ARTICLE:}

Chibuike Ibe, Ngozi Lucy Maduagwu. "Antibacterial activity of Psidium guajava linn. Stem bark extracts on multi drug resistant (MDR) community acquired methicillin-resistant staphylococcus aureus (CA-MRSA)". Journal of Evolution of Medical and Dental Sciences 2013; Vol2, Issue 33, August 19; Page: 6251-6260.

BACKGROUND: medicinal plants are rich in a numerous variety of secondary metabolites of antimicrobial properties. Psidium guajava is one of the parts in folk medicine that has been used for the management of various disease conditions and is believed to be active. As a consequence of the intense fight against infections, bacteria have evolved through numerous defenses against antimicrobial agents. OBJECTIVE: to determine the inhibitory effect of $\mathrm{P}$ guajava Linn. stem bark extracts on multidrug resistant methicillin-resistant Staphylococcus aureus'isolates. MATERIALS AND METHODS: Stock cultures of 51 Staphylococcus aureus'isolated from healthy individuals maintained on nutrient agar slants at $4^{\circ} \mathrm{C}$ were used for this study. The disc diffusion method was used to determine the resistance of the Staphylococcus aureus isolates to methicillin (oxacillin) and to other conventional antibiotic susceptibility discs using standard concentration. The plant materials were extracted and phytochemicals quantified using standard techniques. The agar well diffusion procedure was used for the assessment of the sensitivity of the extracts. RESULTS: nine isolates were resistant to at least 4 of the antibiotics used. The mean inhibition zone diameter (IZD) of the extracts ranged from 10-16 mm with ethanolic extracts exhibiting higher activities. Five isolates showed complete resistance to Psidium guajava extracts. Inhibitory activities of both water and ethanolic extracts were distributed across 4 isolates with organism $\mathrm{E}_{14}$ showing maximum susceptibility profile. The phytochemicals estimated in $\mathrm{mg} / \mathrm{g}$ dry body weight included: total phenol (111.86 \pm 0.47$)$, tannin (141.92 \pm 0.51$)$, flavonoids $(3.37 \pm 0.04)$, vitamin $C(1.67 \pm 0.03)$, saponin (285.76 \pm 0.81$)$, and alkaloid (111.065 \pm 0.38$)$. The extracts of Psidium guajava stem bark though showed high phytochemical contents have relatively low inhibitory activity on the multidrug resistant (MDR) community acquired methicillin-resistant Staphylococcus aureus (CA-MRSA) isolates. CONCLUSION: the results of this study demand the introduction of antimicrobials with novel modes of action.

INTRODUCTION: Staphylococcus aureus (S. aureus) is the most pathogenic species of the known five clinically important species of the genus and is implicated in a variety of infections. ${ }^{25}$ Staphylococcus aureus'has been increasingly implicated in serious, hospital as well as community acquired infections. This pathogen has been particularly efficient at developing resistance to antimicrobial agents, hence, the antimicrobial chemotherapy for the species has always been empirical. ${ }^{11}$ CA-MRSA is susceptible to numerous antimicrobial agents, in contrast to the multidrug resistant (MDR) nosocomial acquired methicillin resistant Staphylococcus aureus'(NA-MRSA) phenotype, because it carries the staphylococcal cassette chromosome mec (SCC mec) type IV or V, rather than type I, II or III. The high virulence of CA-MRSA has been linked to Panton-Valentine leukocidin (PVL), a virulence factor found in most of these strains. ${ }^{21}$ 


\section{ORIGINAL ARTICLE}

Because one criterion for defining a community acquired methicillin resistant Staphylococcus aureus'(CA-MRSA) isolate has been non-multidrug resistance, it was concerning when multidrug resistant (MDR) clones of CA-MRSA were documented in Taipei, Taiwan (strain USA1000, sequence type 59 [ST59] and in San Francisco and Boston (strain USA300, ST8). ${ }^{6}$ The USA300 MDR isolates were all mupirocin resistant. The MDR strain of USA300 was especially concerning because USA300 isolates are virulent and readily transmissible. ${ }^{6}$ The emergence of MDR strains of Staphylococcus aureus, especially the methicillin-resistant Staphylococcus aureus (MRSA), has made the chemotherapy of staphylococcal infections in community and hospital settings increasingly challenging. ${ }^{17}$

As a consequence of the intense fight against infections, bacteria have evolved through numerous defenses against antimicrobial agents. ${ }^{28}$ The main mechanisms whereby the bacteria develop resistance to antimicrobial agents include enzymatic inactivation, modification of the drug target(s), and reduction of intracellular drug concentration by changes in membrane permeability or by the over expression of efflux pumps. ${ }^{27}$

Medicinal plants are rich in a numerous variety of secondary metabolites of antimicrobial properties such as saponins, tannins, alkaloids, alkenyl phenols, glycoalkaloids, flavonoids, sesquiterpenes lactones, terpenoids and phorbol esters. ${ }^{1}$ Psidium guajava (P. guajava)Linn. commonly known as guava is a plant of the family Myrtaceace. The morphology and distribution of the plant have been reported by many authors. ${ }^{10,16} \mathrm{P}$. guajava is one of the parts in folk medicine that has been used for the management of various disease conditions and is believed to be active. The phytochemical analysis revealed that the P. guajava plant extracts contain alkaloids, flavonoids, phenols and tannin which may either individual or in combination are responsible for the antibacterial activity. ${ }^{5}$ Various parts of the plant have been used in traditional medicine to manage conditions ${ }^{5}$, extracts of root bark and leaves are used to treat gastroenteritis, vomiting, diarrhoea, dysentery, wound, ulcers, toothache, cough, sore throat, inflamed gums and a number of other conditions. ${ }^{10}$ The aim of the present study was to determine the inhibitory effect of P. guajava Linn. stem bark extracts on the growth of 9 multidrug resistant community acquired methicillin-resistant Staphylococcus aureus'isolates.

\section{MATERIALS AND METHODS:}

Cell cultures: Stock cultures of 51Staphylococcus aureus'isolated from healthy individuals maintained on nutrient agar slants at $4^{\circ} \mathrm{C}$ at the Department of Plant Science and Biotechnology Laboratory, Abia State University, Nigeria were screened for multidrug resistant strains and used for this study. These stock cultures were sub cultured on mannitol salt agar and incubated at $37^{\circ} \mathrm{C}$ for 24 hours to check for their purity and re-identification. The colonial morphology of the different bacterial isolates were observed and identified accordingly. After 24 hours of incubation of the organisms in a mannitol salt agar plates, a single colony of each bacterium isolate was picked and streaked on a fresh mannitol agar plate and incubated at $37^{\circ} \mathrm{C}$ for another 24 hours. A pure colony of the pure culture was Gram stained and examined for Gram positive cocci in cluster. This was followed by testing the ability for DNAse production on agar plates as well as the ability to produce catalase and coagulase enzymes. Once the identity of each isolate was confirmed by Bergey's manual ${ }^{26}$ according to Al-Jumaily et al 2 , the isolates were each inoculated onto nutrient agar slant, incubated overnight and then stored at $4^{\circ} \mathrm{C}$ until needed for further studies. 


\section{ORIGINAL ARTICLE}

Oxacillin Susceptibility Testing: The oxacillin discs used were procured from Oxoid, Germany. The antimicrobial susceptibility testing of the isolates was determined using the disc diffusion assay as described by Orji et al. ${ }^{19}$ The other discs used were prepared by MAYO diagnostic laboratory, Nigeria according to the recommendation by Clinical and Laboratory Standard Institute. ${ }^{8}$

With a sterile wire loop, few colonies of each of the isolates were emulsified in $5 \mathrm{ml}$ of sterile peptone water to a turbidity corresponding to 0.5 McFarland standard (corresponding to approximately $10^{8} \mathrm{cfu} / \mathrm{ml}$ ). Then $0.5 \mathrm{ml}$ of each inoculum was dispensed onto the surface of dried Mueller Hinton agar plate using sterile Pasteur pipette. These were spread evenly on the agar surface with sterile swab stick (one for each inoculum). The excess inocula were discarded into a disinfectant jar. The inoculated plates were kept on the bench for 3 minutes to dry. The oxacillin disc $(1 \mu \mathrm{g})$ was then placed centrally on the inoculated plates aseptically using a sterile forceps.

The preparations were incubated aerobically for 24 hours at $35^{\circ} \mathrm{C}$. The diameter of zone of inhibition produced by each of the disc was measured, recorded and the isolates were classified as resistant $(\leq 10 \mathrm{~mm})$ or sensitive $(\geq 13 \mathrm{~mm})$ based on the standard interpretative chart as described by the Clinical and Laboratory Standard Institute. ${ }^{8,9}$

Susceptibility Testing of MRSA Isolates to other Conventional Antibiotics: The following antimicrobial sensitivity discs were used: ampicillin $(10 \mu \mathrm{g})$, ciprofloxacin $(5 \mu \mathrm{g})$, ofloxacin $(5 \mu \mathrm{g})$, erythromycin $(15 \mu \mathrm{g})$, gentamicin $(10 \mu \mathrm{g})$, vancomycin $(30 \mu \mathrm{g})$, amoxicillin $(10 \mu \mathrm{g})$, and ceftriaxone $(30 \mu \mathrm{g})$, to determine the susceptibility profile of all the methicillin-resistant strains using the disc diffusion assay as described by Orji et al. ${ }^{19}$ The antibiotic concentration of each disc used was as recommended by Clinical and Laboratory Standard Institute. ${ }^{8}$

With a sterile wire loop, few colonies of each of the isolates were emulsified in $5 \mathrm{ml}$ of sterile peptone water to a turbidity corresponding to $0.5 \mathrm{McFarland}$ standard. Then $0.5 \mathrm{ml}$ of each of the inoculum was dispensed unto the surface of dried Mueller Hinton agar plate using sterile Pasteur pipette (one for each inoculum). These were then spread evenly on the agar surface with sterile swab sticks (one for each inoculum). The excess inocula were discarded into a disinfectant jar. The plates were kept on the bench for 3 minutes to dry. The various discs were placed on the inoculated plates at $25 \mathrm{~mm}$ away from one another and $15 \mathrm{~mm}$ away from the edge of the plates aseptically using a sterile forceps.

The preparations were incubated aerobically for 24 hour at $35^{\circ} \mathrm{C}$. The diameter of the zone of inhibition produced by each of the discs was measured, recorded and interpreted based on the standard interpretative chart as recommended by the Clinical Laboratory Standard Institute. ${ }^{8}$

Plant Collection and Preparation: Fresh stem bark of Psidium guajava (guava) was collected from Uturu, Abia State, Nigeria. The plant materials were identified and authenticated in the taxonomy unit of Department of Plant Science and Biotechnology, Abia State University, Nigeria. The plant materials were chopped into small pieces, air-dried at room temperature and ground into powder using a manual blender. Exposure to direct sunlight was avoided to prevent the loss of active components. The dried powder was stored at $4^{\circ} \mathrm{C}$ until further analysis. Analysis was done at the Department of Plant Science and Biotechnology Laboratory, Abia State University, Nigeria.

Analytical grade ethanol, BDH and distilled water were used for extraction. Reagents for 


\section{ORIGINAL ARTICLE}

phytochemical screening of extracts were freshly prepared using standard methods.

Preparation of Plant Materials Aqueous Extract: This was done according to Soniyaet al. ${ }^{24}$ with minor modification. Fifty grams of dried powdered plant (stem bark) materials was macerated with $500 \mathrm{ml}$ of distilled water and allowed to stand for 24 hours while agitating at regular time intervals. The extract was filtered through Whatman No. 1 filter paper, and evaporated to dryness at $40^{\circ} \mathrm{C}$.

Preparation of Plant Materials Solvent Extract: Fifty gram of dried powdered plant (stem bark) materials was soaked separately for 24 hours in $500 \mathrm{ml} 50 \%(\mathrm{v} / \mathrm{v})$ ethanol. The soaked material was agitated at regular time intervals. After 24 hours the soaked material was filtered using Whatman filter paper No. 1 on separate filtration setups. The final filtrates was collected in wide mouthed evaporating bowls and evaporated to dryness at $40^{\circ} \mathrm{C}$.

The dried extracts were weighed to calculate the extractability percentage. The extracts were stored at $4^{\circ} \mathrm{C}$ until further use.

Sensitivity Test: Agar Well Diffusion Assay: The assay was conducted using agar-well diffusion method described by Esimoneet al. ${ }^{10} \mathrm{An} 80 \mathrm{mg} / \mathrm{ml}$ concentration of both ethanol and water extracts of P. guajava was constituted by dissolving $0.16 \mathrm{~g}$ in $2 \mathrm{ml}$ each of $20 \% \mathrm{v} / \mathrm{v}$ dimethyl sulfoxide (DMSO) and 2-fold serial dilutions made. A single colony of the isolates each was suspended in $2 \mathrm{ml}$ of sterile peptone water. The suspension of each isolate was standardized as stated previously and used to inoculate the surface of the Mueller Hinton agar and the excess fluid drained into disinfectant jar. The inoculated agar surface was allowed to dry and the plates appropriately labeled. Using a cork borer, two wells of $4 \mathrm{~mm}$ in diameter were bored in the inoculated Mueller Hinton agar. With a micropipette, $50 \mu \mathrm{l}$ of each concentration of the test extract was delivered into each well. The plates were left on the bench for 30 minutes to allow the extract to diffuse into the agar. Thereafter, the plates were incubated at $37^{\circ} \mathrm{C}$ for 24 hours. After incubation, the plates were observed for inhibition zones around the wells. The diameters of the zones were measured with metre ruler to the nearest whole millimeter. Each test was carried out thrice and the mean inhibition zone diameter (IZD) recorded to the nearest whole millimetre.

Phytochemical Analyses: These analyses determine the biologically active non-nutritive compounds that contribute to the flavor, colour, and other characteristics of plant parts. Quantitative analyses were done at the International Institute of Tropical Agriculture (IITA), Ibadan.

Preparation of methanolic extract

Methanolic extract of the guava powder (stem bark) was prepared following the method of Chan et al. ${ }^{7}$, by adding $25 \mathrm{ml}$ of methanol to $0.5 \mathrm{~g}$ of sample contained in a covered $50 \mathrm{ml}$ centrifuge tube, and shaked continuously for 1 hour at room temperature. The mixture was centrifuged at $3,000 \mathrm{rpm}$ for 10 minutes, and then the supernatant was collected and store at $-4^{\circ} \mathrm{C}$ for further analysis.

Determination of total phenol content (TPC): The total phenol content of sample methanolic extract was determined according to the Folin-Ciocalteu method reported by Chan et al. ${ }^{7}$ Briefly, $300 \mu \mathrm{L}$ of extract was dispensed into test tube (in duplicates). To this was added $1.5 \mathrm{ml}$ of FolinCiocalteu reagent (diluted 10 times with distilled water), followed by $1.2 \mathrm{ml}$ of $\mathrm{Na}_{2} \mathrm{CO}_{3}$ solution 


\section{ORIGINAL ARTICLE}

$(7.5 \% \mathrm{w} / \mathrm{v})$. The reaction mixture was mixed, allowed to stand for 30 minutes at room temperature before the absorbance was measured at $765 \mathrm{~nm}$ against a blank prepared by dispensing $300 \mu \mathrm{L}$ of distilled water instead of sample extract. TPC was expressed as gallic acid equivalent (GAE) in mg/g material.

Determination of tannin content: Tannin content of sample was determined according to the method of Padmaja ${ }^{20}$ as follows. Sample $(0.1 \mathrm{~g})$ was extracted with $5 \mathrm{~mL}$ of acidified methanol (1\% $\mathrm{HCl}$ in methanol) at room temperature for 15 minutes. The mixture was centrifuged at 3,000 rpm for 20 minutes. $0.1 \mathrm{~mL}$ of the supernatant was added with $7.5 \mathrm{ml}$ of distilled water, $0.5 \mathrm{ml}$ of Folin-Denis reagent, $1 \mathrm{ml}$ of $35 \%$ sodium carbonate solution and diluted to $10 \mathrm{ml}$ with distilled water. The mixture was shaken well, kept at room temperature for 30 minutes and absorbance was measured at $760 \mathrm{~nm}$. Blank was prepared with water instead of the sample. Tannin content was expressed as tannic acid equivalent (TAE) in $\mathrm{mg} / \mathrm{g}$ material.

Determination of total flavonoid content (TFC): Total flavonoid content was determined using aluminum chloride method as reported by Kale et al. ${ }^{14} 0.5 \mathrm{ml}$ of methanolic extract was dispensed into test tube, followed by $1.5 \mathrm{ml}$ of methanol, $0.1 \mathrm{ml}$ of aluminum chloride (10\%), $0.1 \mathrm{ml}$ of $1 \mathrm{M}$ potassium acetate and $2.8 \mathrm{ml}$ of distilled water. The reaction mixture was mixed, allowed to stand at room temperature for 30 minutes, before absorbance was read at $514 \mathrm{~nm}$. TFC was expressed as quercetin equivalent $(\mathrm{QE})$ in $\mathrm{mg} / \mathrm{g}$ material.

Determination of vitamin C content: The vitamin C content of the aqueous extract was determined using the method reported by Benderitter et al. ${ }^{4}$ Briefly, $75 \mu \mathrm{L}$ DNPH $(2 \mathrm{~g}$ dinitrophenyl hydrazine, $230 \mathrm{mg}$ thiourea and $270 \mathrm{mg} \mathrm{CuSO} 4.5 \mathrm{H}_{2} \mathrm{O}$ in $100 \mathrm{ml}$ of $5 \mathrm{M} \mathrm{H}_{2} \mathrm{SO}_{4}$ ) was added to $500 \mu \mathrm{L}$ reaction mixture $(300 \mu \mathrm{L}$ appropriate dilution of hydrophilic extract with $100 \mu \mathrm{L}$ of $13.3 \%$ trichloroacetic acid and distilled water). The reaction mixture was subsequently incubated for 3 hours at $37^{\circ} \mathrm{C}$, then $0.5 \mathrm{ml}$ of $65 \% \mathrm{H}_{2} \mathrm{SO}_{4}(\mathrm{v} / \mathrm{v})$ was added to the medium, and the absorbance was measured at $520 \mathrm{~nm}$, and the vitamin $\mathrm{C}$ content of the sample was subsequently calculated from the calibration curve prepared with ascorbic acid standard.

Determination of total saponin content: Total saponin was determined by the method described by Makkar et al. ${ }^{15} 0.5 \mathrm{~g}$ of sample was extracted with $25 \mathrm{ml}$ of $80 \%$ aqueous methanol by shaking on a mechanical shaker for 2 hours, after which contents of the tubes were centrifuged for 10 minutes at $3,000 \mathrm{rpm}$. In a test tube an aliquot $(0.25 \mathrm{ml})$ of the supernatant was taken to which $0.25 \mathrm{ml}$ vanillin reagent ( $8 \%$ vanillin in ethanol) and $2.5 \mathrm{ml}$ of $72 \%$ aqueous $\mathrm{H}_{2} \mathrm{SO}_{4}$ were added. The reaction mixtures in the tubes were heated in a water bath at $60^{\circ} \mathrm{C}$ for 10 minutes. Then tubes were cooled in ice for 4 minutes and then allowed to acclimatize to room temperature. Subsequently, the absorbance was measured in a UV/Visible spectrophotometer at $544 \mathrm{~nm}$. Diosgenin was used as a standard and the results obtained were expressed as mg diosgenin equivalent per g of sample dry matter.

Determination total alkaloid content: The total alkaloid content of the sample was measured using 1, 10-phenanthroline method described by Singh et al. ${ }^{23}$ with slight modifications. $100 \mathrm{mg}$ 


\section{ORIGINAL ARTICLE}

sample powder was extracted in $10 \mathrm{ml} 80 \%$ ethanol. This was centrifuged at 5000rpm for 10 minutes. Supernatant obtained was used for the further estimation total alkaloids. The reaction mixture contained $1 \mathrm{ml}$ plant extract, $1 \mathrm{ml}$ of $0.025 \mathrm{M} \mathrm{FeCl}_{3}$ in $0.5 \mathrm{M} \mathrm{HCl}$ and $1 \mathrm{ml}$ of $0.05 \mathrm{M}$ of 1,10phenanthroline in ethanol. The mixture was incubated for 30 minutes in hot water bath with maintained temperature of $70 \pm 2{ }^{\circ} \mathrm{C}$. The absorbance of red coloured complex was measured at 510 $\mathrm{nm}$ against reagent blank. Alkaloid contents were estimated and it was calculated with the help of standard curve of quinine $(0.1 \mathrm{mg} / \mathrm{ml}, 10 \mathrm{mg}$ dissolved in $10 \mathrm{ml}$ ethanol and diluted to $100 \mathrm{ml}$ with distilled water). The values were expressed as $\mathrm{mg} / \mathrm{g}$ of dry weight.

RESULTS AND DISCUSSION: Multidrug resistance efflux pumps are recognized as an important component of resistance in both Gram-positive and Gram-negative bacteria. Some bacterial efflux pumps may be selective for one substrate or transport antimicrobials of different classes, conferring a multiple drug resistance (MDR) phenotype. ${ }^{12}$ The isolates were completely resistant to ampicillin, amoxicillin and vancomycin. Ofloxacin appeared to be the most effective though not suitable for treatment in cases of infections with these strains. Orji et al. ${ }^{19}$, defined multidrug resistance as resistant to four or more of the antibiotics tested. Thus, the 9isolates of CA-MRSA showed multidrug resistant ability to the antibiotics used in this study as shown in table 1 . This result is closely related to the findings of Okwuet al ${ }^{18}$, who reported $13(100 \%)$ of the MRSA isolates in their study to be resistant to more than 4 antibiotics. These CA-MRSA strains cause serious skin and soft tissue infections, necrotizing pneumonia, and sepsis in healthy children. ${ }^{22}$ About $66.6 \%$ of the MRSA isolates were resistant to 4 and 6 antibiotics; 33.3\% were resistant to 5,7 and 8 antibiotics used (table 2).

The susceptibility profile of the 9 MDR MRSA isolates to water and ethanolic extracts of P. guajava stem bark is presented in table 3. The inhibitory activities ranged from 10-16 mm zone of inhibition with ethanolic extracts exhibiting higher activity. Five isolates showed complete resistance to P. guajava extracts. Inhibitory activities of both water and ethanolic extracts were distributed across 4 isolates with organism $\mathrm{E}_{14}$ showing maximum susceptibility profile. There is a correlation between the antimicrobial activity and concentration of extracts used.

Anaset al. 3in a related study reported three of the four clinical isolates of MDR Staphylococcus aureus'to be sensitive to the different extracts of the leaf of P. guajava with one clinical isolate showing complete resistance.

The extracts of P. guajava stem bark though showed high phytochemical contents which could individually or in combination inhibit the growth of microorganisms have low inhibitory activity on the MDR MRSA isolates in this study. The main reason for this high level of resistance in the isolates could not be explained but could be due to the inability of the antibacterial principles of the extracts to act as efflux pump inhibitors noted by Kaatz et al. ${ }^{13}$ as an efficient resistant mechanism in Gram-positive bacteria. The efflux pump provides a self-defense mechanism by which antimicrobials are actively removed from the cell. For antibacterials, this results in sublethal drug concentrations at the active site that in turn may predispose the organism to the development of high-level target-based resistance. ${ }^{27,28}$

The phytochemical contents of P. guajava stem bark are presented in table 4 . Phenols have been reported to exert anti-inflammatory and anti-carcinogenic effects. Tannin known to be present in aqueous and methanolic extracts reportedly have protein-binding activities and can interfere with 


\section{ORIGINAL ARTICLE}

substances. ${ }^{27}$ The antibacterial action of tannins against S. aureus, is attributed to the antimicrobial mechanisms of their (I) astringent property (II) toxicity, and (III) complexation of metal ions. ${ }^{10}$ Flavonoids have antioxidant activity and could therefore lower cellular oxidative stress. The high flavonoid content of the P. guajava stem bark may contribute to the medicinal properties. Saponin has been shown to have virucidal activity, reduction of protein digestibility, antimicrobial activity, among others. Alkaloid has been reported to have antibacterial properties and is the most efficient therapeutically significant plant substance. Pure isolated alkaloids and their synthetic derivatives are used as basic medicinal agents due to their analgesic, and antispasmodic properties. As a water-soluble antioxidant, vitamin $C$ is required for healthy bones, gums, teeth and skin, for wound healing, as well as for prevention of common cold and attenuation of its symptoms.

Interestingly, a new class of agent, acyldepsipeptides reported recently kills Gram-positive bacteria via controlled proteolysis. Acyldepsipeptides have been shown to activate a major bacterial protease, caseinolytic protease, bypassing the requirement of its ATPase mediated activation. Caseinolytic protease has a crucial role in the survival and virulence of pathogens during host infection. ${ }^{3}$

CONCLUSION: Multiple drug resistance has become a common feature of many microorganisms especially the human pathogens. The low inhibitory activities of P. guajava extracts indicated the demand for the introduction of alternative medicine with novel modes of action. Antimicrobial agents which act as efflux pumps inhibitors (EPIs) are promising therapeutic agents, as they should restore the activity of standard drugs.

\section{REFERENCES:}

1. Abdallah EM. Plants: An alternative source for antimicrobials. Journal of Applied Pharmaceutical Science 2011; 1(06):16-20.

2. Al-Jumaily EF, Mohamed DA, Khanaka HH. Molecular epidemiology and Antibiotic susceptibility patterns of clinical strains of methicillin resistant Staphylococcus aureus (MRSA) in Sulaimani city-Iraq. Global Advanced Research Journal of Microbiology 2012; 1(6):081-089.

3. Anas K, Jayasree PR, Vijayakumar T, Manish KPR. In vitro antibacterial activity of Psidium guajava Linn. leaf extract on clinical isolates of multidrug resistant Staphylococcus aureus. Indian Journal of Experimental Biology2008; 46:41-46.

4. Benderitter M, Maupoil V, Vergely C. Studies by electron paramagnetic resonance of the importance of iron in the hydroxyl scavenging properties of ascorbic acid in plasma: Effects of iron chelators. Fundamental and Clinical Pharmacology 1998; 12:510-16.

5. Buvaneswari S, Raadha CK, Krishnaveni N, Jayashree S.In-vitro Antimicrobial activity of Psidium guajava against clinically important strains. E-Journal of Life Sciences 2011; 1(1):14-22.

6. Cadilla A, David MZ, Daum RS, Boyle-Vavra S. Association of High-Level Mupirocin and Methicillin-Resistant Staphylococcus aureus at an Academic Center in the Midwestern United States. Journal of Clinical Microbiology 2011; 49(1): 95-100. 


\section{ORIGINAL ARTICLE}

7. Chan E WC, Lim YY, Chew YL. Antioxidant activity of Camellia sinensis leaves and tea from a lowland plantation in Malaysia. Journal of Agriculture and Food Chemistry 2007; 102:12141222.

8. Clinical and Laboratory Standard Institute (CLSI): Performance Standards for Antimicrobial Susceptibility Testing, Seventeenth International Supplement, CLSI document M100-S17. Vol. 27-1 [ISBN 1-56238-625-5], PA, USA, 2007.

9. Clinical and Laboratory Standards Institute (CLSI) Performance standards for antimicrobial susceptibility testing. Approved standard M100-S20. Vol. 30, No. 1. National Committee for Clinical Laboratory Standards, Wayne, PA. USA, 2010.

10. Esimone CO, Attama AA, Mundi KW, Ibekwe NN, Chah KF. Antimicrobial activity of Psidium guajava Linn. stem extracts against methicillin-resistant Staphylococcus aureus. African Journal of Biotechnology2012; 11(89):15556-15559.

11. Gupta R, Nanda S, Barve S. Multi drug resistance in methicillin resistant Staphylococcus aureus (MRSA) isolates from a university hospital of Western India. Journal of Evolution of Medical and Dental Sciences 2013; 2(9):1353-1357.

12. Handzlik J, Matys A, Kieć-Kononowicz K. Recent Advances in Multi-Drug Resistance (MDR) Efflux Pump Inhibitors of Gram-Positive Bacteria S. aureus. Antibiotics 2013; 2:28-45.

13. Kaatz GW, McAleese F, Seo SM. Multidrug Resistance in Staphylococcus aureus Due to Overexpression of a Novel Multidrug and Toxin Extrusion (MATE) Transport Protein. Antimicrobial Agents and Chemotherapy 2005; 49(5):1857-1864.

14. Kale A, Gaikwad S, Mundhe K. Quantification of Phenolics and Flavonoids by Spectrophotometer From -Juglansregia. International Journal of Pharmacy and Biological Sciences 2010; 1:1-4.

15. Makkar HPS, Siddhuraju P, Becker K. Plant secondary metabolites. Totowa: Humana Press Inc., 2007.

16. Noudogbessi JP, Chalard P, Figueredo GA, Alitonou G, Agbangnan P, Osseni A, Avlessi F, Chalchat JC, Sohounhloue DCK. Chemical Compositions and Physical Characteristics of Volatile Extracts of Leaves of Psidium Guajava Linn and Lantana Camara Linn of Benin. Research Journal of Pharmaceutical, Biological and Chemical Sciences2013; 4(1):28-37.

17. Obajuluwa AF, Onaolapo JA, Oyi AR, Olayinka BO. Susceptibility Profile of MethicillinResistant Staphylococcus aureus (MRSA) Isolates to Antibiotics and Methanolic Extracts of Parkiabiglobosa (Jacq) Benth. British Journal of Pharmaceutical Research2013; 3(4).

18. Okwu M, Bamgbala S, Aborisade W. Prevalence of Nasal Carriage of Community-associated Methicillin-resistant Staphylococcus aureus (CA-MRSA) among Healthy Primary School Children in Okada, Nigeria. Journal of Natural Sciences Research2012; 12(4):61-65.

19. Orji I, Nworie A, Eze UA, Agberotimi IO, Okereke EC, Azi SO. The prevalence and antimicrobial susceptibility profile OF methicillin resistant Staphylococcus aureus isolates from clinical specimens in a tertiary hospital, south east Nigeria. Continental Journal of Pharmaceutical Sciences 2012; 6(1):23 - 29.

20. Padmaja G. Evaluation of techniques to reduce assayable tannin and cyanide in cassava leaves. Journal of Agricultural and Food Chemistry 1989; 37:712-716. 
21. Regev-Yochay G, Rubinstein E, Barzilai A, Carmeli Y, Kuint J, Etienne J, Blech M, Smollen G, Maayan-Metzger A, Leavitt A, Rahav G, Keller N. Methicillin-resistant Staphylococcus aureus in Neonatal Intensive Care Unit. Emerging Infectious Diseases 2005; 11(3):453-456.

22. Saravanan M, Anima NA, Tesfaye T. Antibiotic Susceptibility Pattern of Methicillin Resistant Staphylococcus aureus from Septicemia Suspected Children in Tertiary Hospital in Hosur, South India. American Journal of Microbiological Research 2013; 1(2):21-24.

23. Singh DK, Srivastva B, Sahu A. Spectrophotometric determination of Rauwolfia alkaloids, estimation of reserpine in pharmaceuticals. Analytical Sciences2004; 20:571-573.

24. Soniya M, Kuberan M, Anitha S, Sankareswari P. In vitro antibacterial activity of plant extracts against Gram positive and Gram negative pathogenic bacteria. International Journal of Microbiology and Immunology Research 2013; 2(1):001-005.

25. Subraman S, Vignesh S.MAR Index Study and MDR Character Analysis of a few Golden Staph Isolates. Asian Journal of Pharmacy and Life Science 2012; 2(2):151-154.

26. Breed RS, Murray EGD, Smith NR editors. Bergey's Manual of Determinative Bacteriology 7th edition. Baltimore: The Williams \& Wilkins Company, 1957: 464-466.

27. Handzlik J, Matys A, Kieć-Kononowicz K. Recent Advances in Multi-Drug Resistance (MDR) Efflux Pump Inhibitors of Gram-Positive Bacteria S. aureus. Antibiotics2013; 2:28-45.

28. Costa SS, Viveiros M, Amaral L, Couto I. Multidrug Efflux Pumps in Staphylococcus aureus: an Update. The open Microbiology Journal 2013; 7:59-71.

Table 1: Antibiotic resistance pattern of 9 MDR MRSA

\begin{tabular}{|c|c|c|c|c|c|c|c|c|c|}
\hline \multirow{2}{*}{ Drug } & \multicolumn{10}{|c|}{ Isolate } \\
\cline { 2 - 11 } & $\mathrm{U}_{3} \mathrm{~b}$ & $\mathrm{~N}_{11}$ & $\mathrm{E}_{1}$ & $\mathrm{E}_{3}$ & $\mathrm{E}_{9}$ & $\mathrm{E}_{14}$ & $\mathrm{E}_{16}$ & $\mathrm{E}_{17} \mathrm{a}$ & $\mathrm{E}_{17} \mathrm{~b}$ \\
\hline Ampicillin & $\mathrm{R}$ & $\mathrm{R}$ & $\mathrm{R}$ & $\mathrm{R}$ & $\mathrm{R}$ & $\mathrm{R}$ & $\mathrm{R}$ & $\mathrm{R}$ & $\mathrm{R}$ \\
\hline Ciprofloxacin & $\mathrm{S}$ & $\mathrm{R}$ & $\mathrm{R}$ & $\mathrm{I}$ & $\mathrm{R}$ & $\mathrm{R}$ & $\mathrm{I}$ & $\mathrm{I}$ & $\mathrm{I}$ \\
\hline Ofloxacin & $\mathrm{S}$ & $\mathrm{R}$ & $\mathrm{I}$ & $\mathrm{R}$ & $\mathrm{I}$ & $\mathrm{R}$ & $\mathrm{I}$ & $\mathrm{I}$ & $\mathrm{I}$ \\
\hline Erythromycin & $\mathrm{R}$ & $\mathrm{R}$ & $\mathrm{R}$ & $\mathrm{R}$ & $\mathrm{R}$ & $\mathrm{R}$ & $\mathrm{R}$ & $\mathrm{R}$ & $\mathrm{I}$ \\
\hline Gentamicin & $\mathrm{S}$ & $\mathrm{R}$ & $\mathrm{R}$ & $\mathrm{S}$ & $\mathrm{S}$ & $\mathrm{S}$ & $\mathrm{I}$ & $\mathrm{R}$ & $\mathrm{S}$ \\
\hline Vancomycin & $\mathrm{R}$ & $\mathrm{R}$ & $\mathrm{R}$ & $\mathrm{R}$ & $\mathrm{R}$ & $\mathrm{R}$ & $\mathrm{R}$ & $\mathrm{R}$ & $\mathrm{R}$ \\
\hline Amoxycillin & $\mathrm{R}$ & $\mathrm{R}$ & $\mathrm{R}$ & $\mathrm{R}$ & $\mathrm{R}$ & $\mathrm{R}$ & $\mathrm{R}$ & $\mathrm{R}$ & $\mathrm{R}$ \\
\hline Ceftriaxone & $\mathrm{I}$ & $\mathrm{R}$ & $\mathrm{R}$ & $\mathrm{R}$ & $\mathrm{R}$ & $\mathrm{I}$ & $\mathrm{I}$ & $\mathrm{I}$ & $\mathrm{R}$ \\
\hline
\end{tabular}

Table 2: Prevalence of multidrug resistance amongst 9 CA-MRSA isolates

\begin{tabular}{|c|c|c|}
\hline Parameter & Frequency of multidrug resistance & Percentage \\
\hline Resistance to 4 agents & 3 & 33.3 \\
\hline Resistance to 5 agents & 1 & 11.1 \\
\hline Resistance to 6 agents & 3 & 33.3 \\
\hline Resistance to 7 agents & 1 & 11.1 \\
\hline Resistance to 8 agents & 1 & 11.1 \\
\hline
\end{tabular}


Table 3: Susceptibility of MRSA to P. guajava stem bark extract

\begin{tabular}{|c|c|c|c|c|c|c|c|c|c|}
\hline \multirow{2}{*}{$\begin{array}{c}\text { Extract } \\
\text { (Conc. in (mg/ml) }\end{array}$} & \multicolumn{10}{|c|}{ Mean IZD of MDR MRSA isolates (mm) } \\
\cline { 2 - 11 } & $\mathrm{U}_{3} \mathrm{~b}$ & $\mathrm{~N}_{11}$ & $\mathrm{E}_{1}$ & $\mathrm{E}_{3}$ & $\mathrm{E}_{9}$ & $\mathrm{E}_{14}$ & $\mathrm{E}_{16}$ & $\mathrm{E}_{17} \mathrm{a}$ & $\mathrm{E}_{17} \mathrm{~b}$ \\
\hline Water (20) & - & - & - & - & - & - & - & - & - \\
\hline$(40)$ & - & - & - & - & - & 15 & - & 13 & - \\
\hline Ethanol (20) & - & - & - & - & - & 12 & - & - & - \\
\hline$(40)$ & 11 & - & - & - & 10 & 16 & - & - & - \\
\hline
\end{tabular}

Table 4: Total phenol, tannin, flavonoids, vitamin C, saponin, and alkaloid expressed in mg/g dry body weight.

\begin{tabular}{|c|c|}
\hline Phytochemical & P. guajava (stem bark) \\
\hline Total phenol & $111.86 \pm 0.47$ \\
\hline Tannin & $141.92 \pm 0.51$ \\
\hline Flavonoids & $3.37 \pm 0.04$ \\
\hline Vitamin C & $1.67 \pm 0.03$ \\
\hline Saponin & $285.76 \pm .81$ \\
\hline Alkaloid & $111.065 \pm 0.38$ \\
\hline
\end{tabular}

Data represent the mean \pm standard deviation of duplicate readings.

\section{AUTHORS:}

1. Chibuike Ibe

2. Ngozi Lucy Maduagwu

\section{PARTICULARS OF CONTRIBUTORS:}

1. Assistant Lecturer, Department of Microbiology, Abia State University, PMB 2000, Uturu, Abia State, Nigeria.

2. Research Assistant; Department of Microbiology, Abia State University, PMB 2000, Uturu, Abia State, Nigeria.

\section{NAME ADDRESS EMAIL ID OF THE} CORRESPONDING AUTHOR:

Chibuike Ibe,

Microbiology Department,

Abia State University, PMB, 2000,

Uturu, Abia State, Nigeria.

Email- chibuike_ibe@yahoo.co.uk

Date of Submission: 01/08/2013.

Date of Peer Review: 03/08/2013.

Date of Acceptance: 06/08/2013.

Date of Publishing: 16/08/2013 